\title{
CONSTRUCTION AND MEASUREMENT TECHNIQUES FOR THE APS LEUTL PROJECT RF BEAM POSITION MONITORS ${ }^{*}$
}

\author{
Anthony J. Gorski," Robert M. Lill, Accelerator Systems Division, Advanced Photon Source, \\ Argonne National Laboratory, 9700 South Cass Avenue, Argonne, IL 60439 U.S.A.
}

\section{Abstract}

The design, construction, and assembly procedure of $24 \mathrm{rf}$ beam position monitors used in the Advanced Photon Source low-energy undulator test line and linear accelerator (linac) are described. Beam stability as well as beam positioning capabilities are essential to the LEUTL project. A design objective of the LEUTL facility is to achieve better than $1-\mu \mathrm{m}$ resolution. The highest care was used in the mechanical fabrication and assembly of the BPM units. The latest experimental results using these BPMs will be presented.

\section{INTRODUCTION}

The Advanced Photon Source (APS) low-energy undulator test line (LEUTL) was designed to test prototype undulators and to develop the technology necessary for a fourth-generation synchrotron light source [1]. The LEUTL beam position monitor (BPM) system employs both $4-\mathrm{mm}$ buttons and S-band stripline BPM detectors as shown in Fig. 1 and schematically in Fig. 2. The total length of the stripline assembly is $83 \mathrm{~mm}$, the electrode length is $28 \mathrm{~mm}$, and the inner electrode diameter is $35 \mathrm{~mm}$, the same as the linac vacuum chamber ID. The metal electrodes form 50-ohm transmission lines between each of the four blades and the vacuum chamber housing. The downstream end of the

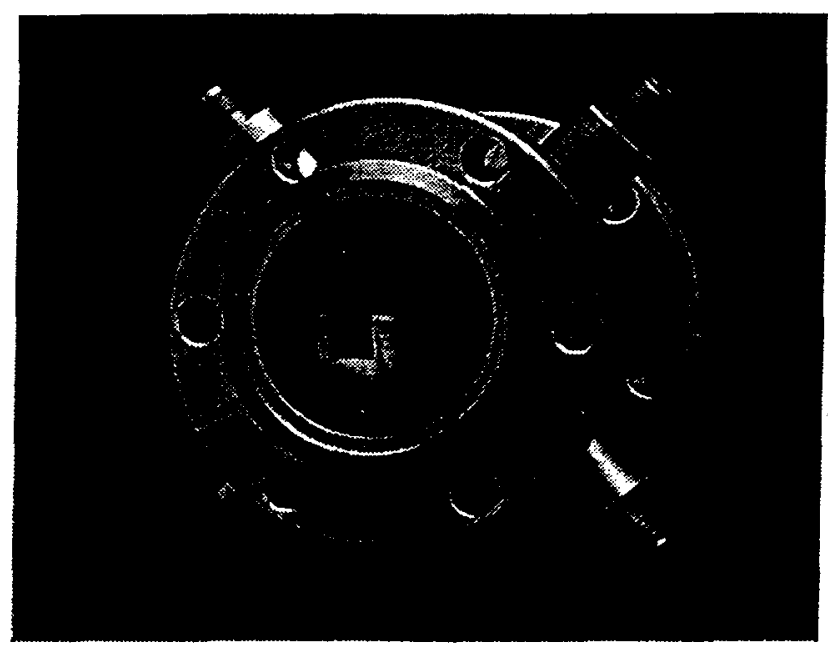

Figure 1: The LEUTL shorted S-band quarter-wave four-plate stripline BPM

\footnotetext{
* Work supported by the U.S. Deparment of Energy. Office of Basic Energy Sciences, under contract number W-31-109-ENG-38. \#Erniil: gorski@aps anl.gov
}
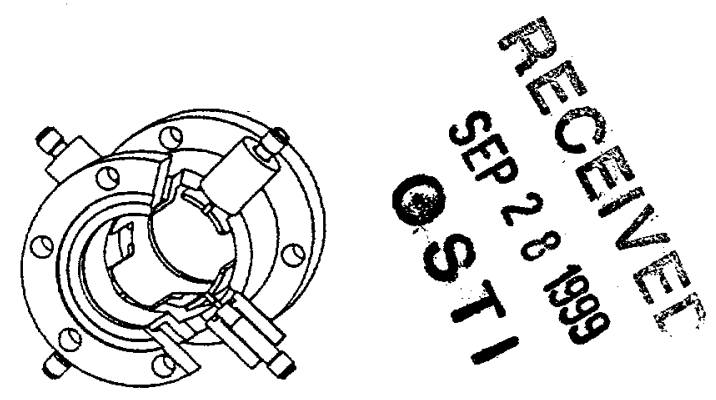

Figure 2: Cut away 3D drawing of LEUTL-BPM showing internal structure

transmission line is electrically shorted, which also provides mechanical strength and rigidity to support the stripline pickup. This technique of supporting the stripline results in a TEM wave velocity induced on the stripline that is approximately equal to the beam velocity.

The receiver topology used is a monopulse amplitude to phase (AM/PM) technique for measuring the beam position in the $x$ and $y$ axes and a logarithmic amplifier channel for measuring the beam intensity. The striplines are installed with the blades rotated $\mathbf{4 5}$ degrees from axis to operate in the monopulse system. The stripline output signals are conditioned by the down converter monopulse comparator (DCMC). The DCMC provides signal filtering and down converts the $2856-\mathrm{MHz}$ position information to $351 \mathrm{MHz}$. It also generates horizontal and vertical difference and sum signals through a 180-degree hybrid rat race network.

\section{DESIGN}

The LEUTL BPM stripline was designed to operate at $2856 \mathrm{MHz}$ and is similar to that implemented for the APS linac [2]. The design was optimized using standard design equations [3] and then empirically refined. The design goal was to enhance port isolation, reduce reflections, and increase BPM stripline production yields. The impedance of the stripline was optimized to $50 \mathrm{ohms}$ to match that of the SMA feedthrough. Figure 2 illustrates the internal structure and Fig. 3 shows how the output of the stripline is connected via a short tantalum ribbon to the molybdenum feedthrough connector. This technique minimizes the electrical mismatch that is typically encountered when transitioning from the stripline to the feedthrough. The ribbon also acts as a strain relief for any forces acting on the ceramic vacuum seal. 


\section{DISCLAIMER}

This report was prepared as an account of work sponsored by an agency of the United States Government. Neither the United States Government nor any agency thereof, nor any of their employees, make any warranty, express or implied, or assumes any legal liability or responsibility for the accuracy, completeness, or usefulness of any information, apparatus, product, or process disclosed, or represents that its use would not infringe privately owned rights. Reference herein to any specific commercial product, process, or service by trade name, trademark, manufacturer, or otherwise does not necessarily constitute or imply its endorsement, recommendation, or favoring by the United States Government or any agency thereof. The views and opinions of authors expressed herein do not necessarily state or reflect those of the United States Government or any agency thereof. 


\section{DISCLAIMER}

Portions of this document may be illegible in electronic image products. Images are produced from the best available original document. 


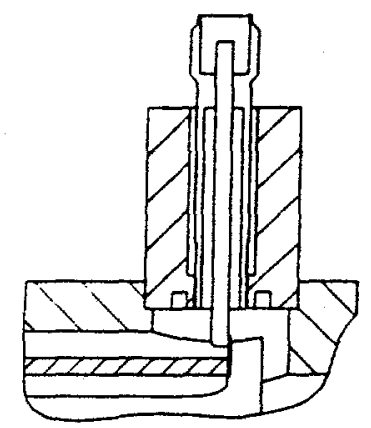

Figure 3: Cross-sectional view showing attachment of the SMA feedthrough center conductor to the internal blade by means of a thin tantalum ribbon

The length of the stripline, $28 \mathrm{~mm}$, was optimized for maximum isolation at $2856 \mathrm{MHz}$ between ports. This is also the electrical length, which offers the maximum amplitude and zero crossing phase at $2856 \mathrm{MHz}$. This was approximately $7 \%$ longer than the theoretical quarter wavelength of $26 \mathrm{~mm}$. The inductive mismatch at the transition area shown in Fig. 3 could account for this difference.

\section{COMPONENTS AND FABRICATION}

The 50-ohm feedthrough used was a Kamen Instrument model 853872 . The material of the outer body is $\mathbf{3 1 6}$ stainless steel and the center conductor is TZM molybdenum per ASTM B365. The vacuum seal insulator material is $\mathrm{Al}_{2} \mathrm{O}_{3}$-strengthened borosilicate with 130,000 psi compression strength. The feedthrough is specified with an operating temperature range of $-269^{\circ}$ to $300^{\circ}$ Celsius and a hermeticity of $<1 \times 10^{-11} \mathrm{cc} \mathrm{He} / \mathrm{s}$.

Previous experience with assembling these types of BPMs resulted in a high failure rate of feedthrough during the welding process. The major cause of the failure is believed to be caused by the differential linear expansion of the stripline and the molybdenum center conductor, which were welded directly together. In the new design a short piece of tantalum ribbon sheet is used to bridge the stripline and molybdenum center conductor as shown in Fig. 3.

The fabrication of the BPM starts with standard stock 316 stainless steel. The four quarter-wave plates on the electrode port are cut by a traveling wire-type EDM machine. This cutting process used a brass wire for an initial cut, then a smoothing cut followed by an acid washing of the finished part to remove any brass from the stainless steel surface. Since the EDM process does not involve mechanical energy, the hardness or the strength of the workpiece is not affected by the removal rate.

The traveling wire EDM procedure is also used to cut the 0.064-inch TZM molybdenum center conductor to the required length. The conductor is held by the free end such that no stress is applied to the insulator/outer body vacuum seal. Finally, tantalum strips are cut to length for the feedthrough to quarter-wave plate connection.

\section{ASSEMBLY PROCESS}

The assembly process starts with cleaned stainless steel components and chemically etched feedthrough center conductors, and tantalum strips. At this stage, all parts are handled with proper gloves, and etched ports are kept in closed vials. Since the etched parts are e-beam brazed within 12 to 24 hours after etching, a dry nitrogen atmosphere is not necessary.

First the feedthroughs are e-beam welded to the connector and vacuum leak tested. The next step is the ebeam silver wetting of the feedthrough conductor by means of thin silver foil. Then the brazing operation couples the tantalum strip to the molybdenum conductor, and the completed units are stored until final assembly.

The two halves of the body unit are TIG welded together, and the four completed connector columns are aligned and TIG welded to the body of the conductor piece. It is necessary for the columns to be perpendicular to the conductor surface and aligned such that the final ebeam brazing to the face of the electrode plate can be made. After a final vacuum leak check, the conventional welding of the two rotatable flanges completes the assembly.

\section{MEASURED PERFORMANCE}

The stripline was measured using the HP $8510 \mathrm{C}$ network analyzer with the time domain reflectometer (TDR) option. Using the TDR in the low pass mode, stripline mismatches can be located and characterized. The stripline return loss was measured using a gating technique that electrically eliminates all other reflections. The gate is a time filter in which specific mismatches such as the short at the end of the line can be filtered out of the measurement. Measuring only the stripline, a 20$\mathrm{dB}$ return loss at $2856 \mathrm{MHz}$ was realized.

The electrical length of the stripline was optimized to $28 \mathrm{~mm}$ to improve port isolation. The isolation between ports measures typically about $60 \mathrm{~dB}$ at $2856 \mathrm{MHz}$ (see Fig. 4), which is about a $25-\mathrm{dB}$ improvement over the original design.

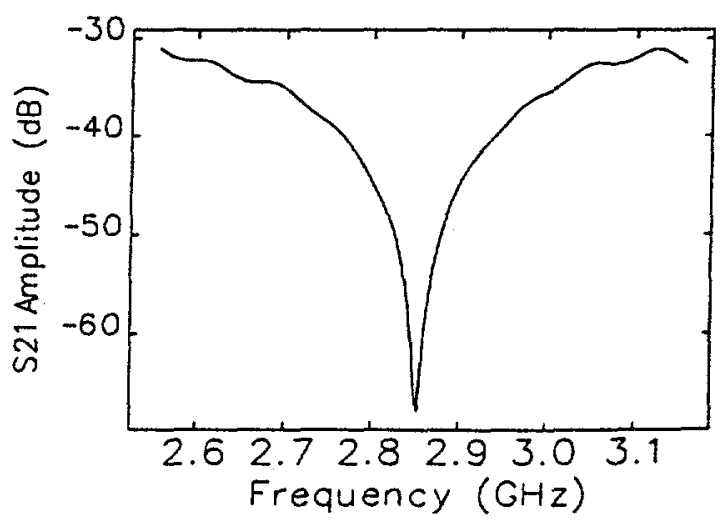

Figure 4: Measured port isolation 
The stripline and BPM electronics were tested on the bench using a wire stretched through the stripline vacuum chamber. The vacuum chamber was mounted on an adjustable two-axis precision micrometer table that was used to simulate beam position motion. An if isolator was implemented at the input of the chamber to properly match the source, masking the input VSWR of the chamber transition. The results indicate a linear range of operation of about $\pm 10 \mathrm{~mm}$ from the center of the chamber, as shown in Fig. 5. The horizontal position data measured coincide approximately with the calculated values shown in Fig. 5. The deviation from the theoretical response is shown in Fig. 6. The measured vertical response results are similar.

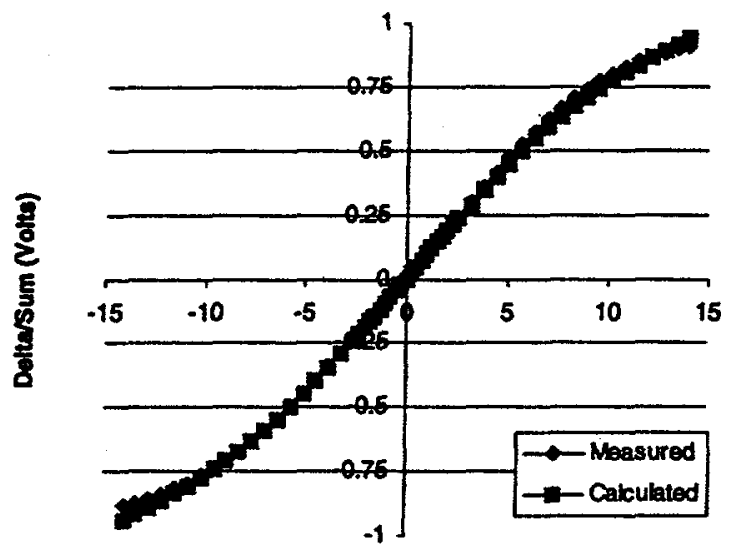

Horlzontal Postlion $(\mathrm{mm})$

Figure 5: Delta/sum vs. horizontal position wire test data

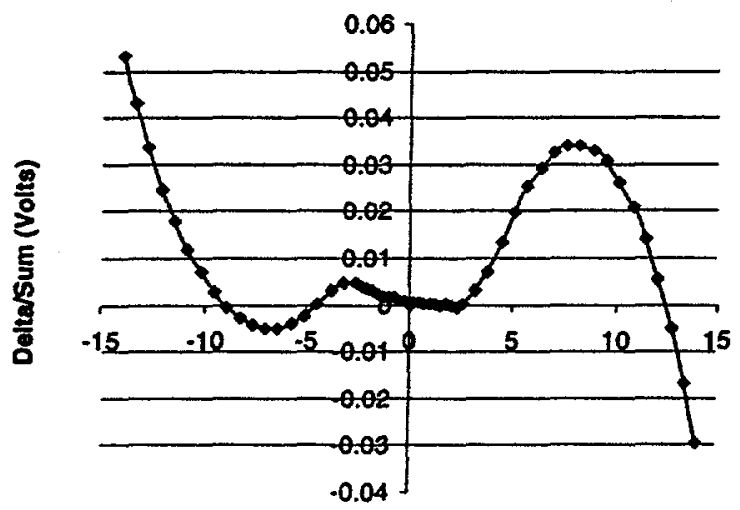

Horizontal Position (mm)

Figure 6: Deviation from expected response

The LEUTL BPM system must provide high-resolution beam position at rated operating beam currents. The AM/PM phase detector has a linear voltage vs. phase output with a sensitivity of 90 degrees/volt. The AM/PM transfer function can be described as follows:

$$
E_{\text {out }}=\frac{4}{\pi} \tan ^{-1} \frac{\Delta}{\Sigma}
$$

where $E_{\text {out }}$ is the receiver output.
It is desirable to operate the BPM system such that the maximum receiver input $(+10 \mathrm{dBm})$ is realized in order to maximize beam position resolution. The output noise of the receiver can be described as follows $[3,4]$ :

$$
\begin{aligned}
& \left(\frac{\Delta}{\Sigma}\right)_{\text {sensitivity }}=1 \text { volt } / 90 \text { degrees }, \\
& \Delta \theta_{\text {phasejitter }}=1 / \sqrt{S N R} \text { rads, }
\end{aligned}
$$

Receiver Output Noise $=$ Phase Jitter $\times\left(\frac{\Delta}{\Sigma}\right)_{\text {sensitivity }}$,

$$
\text { Resolution limit } \equiv \frac{\mathrm{b}}{2 \sqrt{2}} \sqrt{\frac{\mathrm{Pn}}{\mathrm{Ps}}},
$$

where $b$ is half aperture, Ps is the signal power on a single electrode, and $\mathrm{Pn}$ is the noise power.

The thermal noise power (KTB) for the $20-\mathrm{MHz}$ bandwidth is $-91 \mathrm{dBm}$. Since there are two channels (delta and sum), the noise is incoherent and will add in quadrature for a total equivalent noise of $-88 \mathrm{dBm}$. The receiver input is $+10 \mathrm{dBm}$ at rated beam current, yielding a signal-to-noise ratio (SNR) of $98 \mathrm{~dB}$. This corresponds to a resolution limit of about $1 \mu \mathrm{m}$ for a $34.8-\mathrm{mm}$ diameter aperture.

\section{CONCLUSION}

The assembly of 24 if beam position monitors has been successfully accomplished with a yield of $100 \%$. The preliminary bench test results have been encouraging and further tests are ongoing. Operational and commissioning data will be obtained as the LEUTL facility becomes operational in the next few months.

\section{ACKNOWLEDGEMENTS}

The authors would like to acknowledge Glenn Decker, Raymond Fuja, and Dean Walters for many helpful discussions. Chuck Gold and Robert Keane provided valuable electrical measurement and assembly expertise. The mechanical advice of Frank DePaola and William Totter proved to be most useful. And finally, the e-beam expertise of Robert Sommer and Robin Reierson, and etching assistance of Richard Lee made it all look simple.

\section{REFERENCES}

[1] S. Milton, J. Galayda, E. Gluskin, "The Advanced Photon Source Low-Energy Undulator Test Line," 1997 Particle Accelerator Conference, Vancouver, BC, Canada, IEEE (1998), pp. 877-879.

[2] R. Fuja, Y. Chung. "The APS Linac Beam Position Detectors and Electronics," $4^{*}$ Accelerator Instrumentation Workshop, LBL, Berkeley, CA, 1992, pp. 248-255.

[3] R. Shafer. "Beam Position Monitoring," AIP Conference Proceedings 212, Accelerator Instrumentation, Upton, N.Y., 1989. pp. 26-58.

[4] Watkins Johnson, "Monopulse Receiver Technical Proposal," WJ-253199, Vol. I, 1992 